\title{
The Development of an Instrument to Measure Stigmatization: factor analysis and origin of stigmatization
}

\author{
Rahman Haghighat, MBChB, MRCPsych, \\ PhD (UCL), \\ Consultant Psychiatrist and Psychotherapist, \\ Department of Psychiatry, University \\ College London Medical School, United \\ Kingdom
}

UNITED KINGDOM

\begin{abstract}
Assessment of stigmatization and understanding of its roots are gaining more importance as its effect on the prognosis of mental health is recognized. A search with Medline showed that there are instruments assessing stigmatization, most containing misconceptions, and regrettably none with adequate reliability and validity. To develop a reliable and valid instrument for research into stigmatization, and to define the structure of stigmatization by factor analysis of the results, about two thousand items from patients' own explanatory models, user groups' ideas, relatives' and social workers' accounts were scrutinized by the author and an independent observer. The items were simplified and rephrased so that they each contained a single idea expressed in clear language. Items were excluded on the grounds of redundancy, culture-boundness or representing factual knowledge rather than attitude. The draft of the instrument was field-tested, and rigorous assessments proved its reliability and validity. Factor analysis derived three factors indicating social, psychological and evolutionary foundations of stigmatization. The result is the Standardized Stigmatization Questionnaire, version 1 (SSQ1) which is now being used in several research centres in Europe. The Unitary Theory of Stigmatization resulting from this study has contributed to a new understanding of the meaning of stigmatization.
\end{abstract}

\section{Introduction}

For about a decade there have been calls from psychiatric research centres for a reliable and valid instrument for the measurement of stigmatization. This is in recognition of the fact that stigmatization is likely to worsen the prognosis mental illness (Haghighat 2003), and in societies where stigmatization is more intense the prognosis of conditions such as schizophrenia is worse (Littlewood 1998). A search of literature with Medline showed that there were instruments 
reporting to assess the stigmatization of mental illness. These included the Custodial Mental Illness Ideology (CMI) Scale by Gilbert and Levinson (1956), Cumming \& Cumming's stigmatization scale (1957), Opinion about Mental Illness (OMI) by Cohen \& Struening (1962), Community Mental Health Ideology (CMHI) by Baker \& Schulberg (1967), Community Attitudes to Mental Illness (CAMI) scale by Taylor \& Dear (1981), and intercultural stigmatization questionnaire by Littlewood (1998). Two main issues were identified in these instruments: first, the lack of a social desirability scale or at least a recommendation to use it, and second, misconceptualizations of stigmatization following factor analysis which delayed understanding of the meaning of stigmatization (see below).

\section{Methods}

The objective of this piece of work was to design a stigmatization scale, usable with different groups: patients, family, community and professionals. The scale was developed in three phases. The final product, SSQ1, is composed of two parts: Part I assessing participants' perception of stigmatization by others, and part II assessing participants' predisposition to enact stigmatization. Ethical approval was obtained from the Middlesex Hospital Trustees in London, and participants were included after written informed consent was obtained.

\section{Phase I, Constitution of the First Draft}

The first items of the draft came from more than 120 patients' accounts in groups in which the author acted as therapist in four hospitals in London (University College Hospital, Middlesex Hospital, Whittington Hospital, St Lukes Woodside Hospital); and the ideas of 358 patients, relatives and social workers during community assessments the author did in homes, hostels, prisons, police stations, streets, day centres and homeless shelters; and from the views of patients and relatives with whom the author worked in Birmingham, Tehran, London and Paris. The theme underlying more than 2000 comments, explanatory models or points of view were determined (e.g. expressed feelings of rejection, people's fear of patients, feelings of being avoided, being disliked in the neighbourhood, resources for mental health services, employment and work discrimination, etc.). The most frequent comments under each theme were selected and a question was formulated on the basis of the theme, e.g., from the theme of 'isolation, lack of a relationship, difficulty getting married' the question 'Would most people be happy if a person with schizophrenia married their daughter or sister?' emerged. This method resulted in 26 questions.

Another set of 26 items from Littlewood (1998) were considered to have been as rigorously screened and selected as the items from the phase I of this work, and also without the influence of any preconceived theory about the origin of stigmatization. The 26 items from this work were pooled together with the 26 items from Littlewood (1998) (with permission) in order to perform a metaselection. As people's point of view on stigmatization are likely to be similar in different societies, it is not surprising that three of the items in the draft were very similar to three from Cohen and Struening (1962) and one from Cumming \& Cumming (1957). The author and an independent observer then 
scrutinized the pool of 52 items and the questions were simplified and rephrased so that they each contained a single idea expressed in clear language. Out of the 52 items, 32 were excluded on grounds of redundancy (for example, 'Do most people think a patient with schizophrenia can be dangerous' and 'Do most people believe a person with schizophrenia can become physically violent'; being clearly culture bound, for example, 'Can a person from a high cast (e.g., a Brahmin) develop schizophrenia?' or assessing factual knowledge rather than attitude 'Is it true that severe mental illness affects one to two per cent of the population?' After the exclusions, 20 questions remained constituting the basis of the instrument.

It is recognized that a five-point Likert scale draws more data from respondents than a four point one. The higher gradation of responses makes assumptions about treating ordinal data as quantitative and the application to such data of factor analysis more acceptable (Rodeghier 1996). Yet contrary to situations in which one assesses more neutral issues, such as preference for a certain product, five- (or a higher number) point Likerts are not necessarily suitable when assessing sensitive matters such as stigmatising attitudes because, firstly, it reduces people's cooperation by making the questions lengthy; and secondly, opting for a five-point scale means including a midpoint option such as "I have no particular view on this issue" which acts as a convenient means of avoiding self-revelation. Therefore, a fourpoint scale was preferred for this work.

Including a vignette was felt to give some context to the abstract idea of mental illness and engage participants in the process of responding to the questionnaire. Vignettes are also likely to allow respondents to react in a manner comparable to their actual behaviour (Brockman et al. 1979). There- fore, the 20 questions were preceded by a short vignette from Littlewood (1998) about a man who becomes ill, and as illness, schizophrenia was chosen as the archetypal mental illness attracting considerable stigmatization in recent surveys (e.g., Crisp et al. 2000) though the same vignette can be used to assess the stigmatization of someone with any other mental illness, by replacing the diagnosis at the end of the vignette. To reduce the effect of social desirability, instructions stressed that participants' names are not required and that there are no right or wrong answers and that the experimenters are just interested in the participants' opinion (Appendix I). An effort was made not to give a detailed description, in the vignette, of the man's behaviour precisely in order to elicit any stigmatizing attitudes based on the mere presentation of someone with the diagnostic label of 'schizophrenia' as it happens in real world situations. It was felt likely that altering gender and age would elicit a different response and indeed they can be used as independent variables by future investigators who may get interesting differential results.

The questions asked respondents how they thought 'most people' but not themselves react to the man described in the vignette. This was done in order to elicit participants' perception of the stigmatization by the community. Each question had four possible responses: (Yes, very much; Yes, a little, No, not so much; No, not at all), or, (Definitely yes; Perhaps yes; Perhaps no; Definitely no) etc. depending on the question. A score of 1 was given to the least and a score of 4 to the most perception of stigmatization. Questions were designed such that to obtain a high score the respondent needed to answer yes very much to some questions and no, not at all to others. This was to minimise the influence of response sets produced by yea-sayers and nay-sayers. 
Part II of the draft assessing predisposition to enact stigmatization contained the same vignette and the 20 questions in Part I with the difference that the questions now asked how the respondents themselves felt, thought about, or acted towards the man in the vignette. This was done by replacing the subject of the questions, 'most people', with 'you'. For example 'Would most people be happy to eat food which he has cooked?' was replaced by 'Would you be happy to eat food which he has cooked?'. In this way the second part of the questionnaire was constructed to assess predisposition in participants to enact stigmatization towards patients.

\section{Phase II, Field Testing of the Questionnaire for Simplicity and Clarity}

The 20-item questionnaire was field-tested on 30 users recruited by a random draw for them to comment on the clarity of the questionnaire, and minor changes were made by the author in the wording to make the language clearer and simpler (Table I).

\section{Phase III: factor analysis; validity and reliability}

Factor analysis and its main method, principal component analysis, followed by varimax rotation, is a statistical procedure that helps reduce data to their essential components. It looks at responses to all the questions in a questionnaire, prunes the data that do not seem to be essential, and regroups and summarises the essential ones (Rodeghier 1996). The procedure extracts question sets, called FACTORS, each measuring an underlying tendency or a hidden concept that, when interpreted properly, helps understand the essence of what is being measured. So factor analysis can be used to understand basic attitudes which are likely to be linked to the origin of stigmatisation.

The 20-item questionnaire was tested on 256 patients with schizophrenia, and their relatives selected by a random number table from the list of patients with a diagnosis of schizophrenia, and their relatives from four inner city London hospitals of Camden \& Islington Community Mental Health NHS Trust. Only patients in remission were included which ensured they are not going to over-perceive stigmatization due to paranoid or depressive states. A brief, reliable and separately validated 4-item social desirability (SD) scale (Haghighat 2001a, also obtainable from the author by correspondence) was used in conjunction with part I assessing predisposition to enact stigmatization. Participants located on the extreme centiles of the SD scores (38 participants above 85 centile) were excluded from all computations. In the factor analysis, factors with Eingenvalues above 1 were selected. Items with high loading figures (above 0.500) in each factor were subjected to alpha reliability analysis. Items which reduced alpha for a given factor to less than 0.70 were excluded. An oblique rotation gave identical factors and selected the same questions after reliability analysis. The reliability of the whole questionnaire was assessed using Cronbach Alpha method. High loadings of the items in factor analysis constitute a necessary (though not sufficient) condition for their validity, representing high correlation between each item of a factor and the concept represented by that factor (Rodeghier 1996). In addition this, face, criterion and content validity were examined. The items of the questionnaire were scrutinised for face validity by an independent observer. The content validity was examined by systematically scrutinising whether each item covered an aspect of stigmatization and 
Table I

The list of questions used in the SSQ draft assessing perception of stigmatization. Principal Component Analysis, Varimax Rotation with Kaiser Normalization. Items with high loading figures (above 0.500) in each factor were subjected to alpha reliability analysis. Items that reduced alpha for a given factor to less than 0.70 were excluded. An oblique rotation gave identical factors and selected the same questions after reliability analysis

Questions

Rotated Component Matrix

1. Would most people be happy to sit next to this man on a bus?

2. Would most people be happy to eat food which he has cooked?

$\begin{array}{ccc}1 & 2 & 3 \\ 0.702 & 0.276 & 0.051\end{array}$

3 . Would most people be happy to work in the mental hospital he and other people with similar problems are treated?

4. Would most people avoid talking to him if possible?

$0.657 \quad 0.248 \quad 0.153$

5. Would most people think he will be able to return to a completely normal life?

$0.639 \quad 0.044 \quad-0.137$

$0.589 \quad 0.229 \quad 0.279$

6. Would most people think this man is a bad person?

$\begin{array}{lll}0.576 & 0.301 & 0.098\end{array}$

$0.532 \quad 0.124 \quad 0.516$

7. Would most people think he should stay in hospital for his whole life? $\quad \begin{array}{llll}0.516 & 0.214 & 0.379\end{array}$

8. If social services open a day centre for people like him in their neighbourhood, would most people have any objection?

$0.349 \quad 0.260 \quad 0.264$

9. Would most people be happy if this person became the teacher of their children?

10. Would most people be happy if he married their sister?

$\begin{array}{lll}0.112 & 0.793 & 0.116\end{array}$

$\begin{array}{lll}0.169 & 0.775 & 0.064\end{array}$

11. Would most people be happy if he were to work together with them in their workplace?

$\begin{array}{lll}0.326 & 0.675 & 0.008\end{array}$

12. Would most people be frightened if this man came to live next door to them? $\quad 0.412 \quad 0.524 \quad 0.033$

13. Would most people think that he should take part in the making of important family decisions?

14. Would most people think he is very likely to become physically violent?
15. If he is married, do most people think that, because of his condition,

$\begin{array}{lll}0.434 & 0.498 & 0.029\end{array}$

$0.421 \quad 0.431 \quad 0.233$ the law should allow his wife to divorce him without his consent?

16. Do most people think one of the main causes of his condition is a lack of moral strength or will power?

$0.213 \quad 0.415 \quad 0.382$

$\begin{array}{lll}-0.004 & -0.028 & 0.767\end{array}$

$0.112-0.017 \quad 0.735$

17. Do most people think his condition is a punishment for bad deeds?
18. Do most people think he has developed his condition to avoid the difficult problems of everyday life?

19. Do most people think he has become a failure in his life?

20. Do most people think he should be allowed to vote?

$0.113 \quad 0.312$

0.621

$\begin{array}{lll}0.343 & 0.362 & 0.459\end{array}$

whether the set of all items covered all constitutive features of stigmatization such as branding, rejection, devaluation and unjustified discrimination as expressed in the comments and explanatory models.

\section{Results}

It was acknowledged that the items 'made sense' on the surface, in their formulation, wording and focus, as valid measures of stigmatization. An evaluation of face validity is a gross one and cannot be objective, yet the involvement of an independent observer gave that evaluation a measure of independence. For criterion validity, it was considered to validate the new instrument with the help of an existing one taken as valid but as older instruments contain conceptual controversies (see Discussion) this would have been 'validating' the new instrument with another instrument one assumes to lack validity. 
There is always the possibility of attending to criterion validity further, in future experiments, by comparing subjects' scores in this questionnaire with their behaviour in real life situations. The assessment of content validity showed that the set of all items covered all features of stigmatization expressed in the comments and explanatory models. The three factors extracted were identified as Social Self-Interest; Psychological SelfInterest and Evolutionary Self-Interest (Table II). The rationale for the naming of the factors is presented under Discussion. The factors were found to have a moderately good reliability (Cronbach Alpha coefficients above 0.74 ). These coefficients are a measure of the internal consistency of the items within each factor. They represent how much the items measure the same thing and, in a sense, hang together. In addition to the internal reliability of items within each factor, the reliability of all the 13 items of the questionnaire was measured on thirty participants (Alpha $=$ 0.9901 for Part I; 0.8819 for Part II). These coefficients indicate a high degree of reliability of the SSQ, and confirm that though the three factors constitute substructures of stigmatization, the 13 items as a whole are likely to refer to a single dimension (stigmatization) and the questionnaire's total score is likely to be a sufficient statistic measuring total stigmatization.

\section{Discussion}

\section{A) Design Features}

Though this study considered schizophrenia as a prototypical stigmatised condition, there is no reason to believe that the essence of stigmatization should be any different when directed at ethnic minorities, people with AIDS or those with a variety of other blemishes. What are likely to vary are the intensity of stigmatization and the relative weight of each of its factors rather than its deep meaning.

Patients and relatives are primary targets of stigmatization and therefore are acutely aware of its manifestation in the community. Precisely for this reason, it was expected that the factor analysis of the results obtained from patients and relatives as subjects was more likely to pinpoint the factors which are nearer to the central meanings of stigmatization.

What plagues all attitudinal questionnaires especially those assessing predisposition to enact stigmatization is the Social Desirability (SD) factor, i.e., participants' tendency to give socially 'desirable' (and so sometimes false) answers (in order to put forward a more acceptable self-image). Participants may respond in a socially desirable manner to questions probing sensitive areas of private feelings and behaviour as for example there is no flesh-and-blood psychiatric patient asking to rent a room in their homes. This is a defence (presenting oneself as a 'good', 'fair' and 'impartial' citizen against the 'threat of judgment' made by the probing questions). Though the effect of this factor is well known in experimental psychology, none of the old stigmatization scales has either an integrated SD scale, or has at least come with a recommendation to use a standard SD scale. Considering the above, it was felt that what the existing instruments measured was distorted at least by the SD factor. This is likely to have affected the validity of these questionnaires in that what is measured is not strictly speaking stigmatization.

\section{B) Concept underlying factors}

What are the deep meaning and motivation for stigmatization? Some existing 
Table II

The SSQ1 containing thirteen questions regrouped in three reliable and valid factors. The loadings indicate the correlation between each item and what the factor measures. The Corrected Total-Item Correlation and Cronbach Alpha are measures of reliability and internal consistency of the items within each factor. The same questions are used to assess the tendency to enact stigmatization by replacing 'most people' with 'you' in all the questions. After cancelling from the calculation, the effect of those draft questions contributing little to the final form (e.g., questions 19, Table I), the total variance of the extracted factors is nearly $60 \%$ which is moderately good

\begin{tabular}{|c|c|c|c|c|}
\hline Factor & Questions & Loading & $\begin{array}{l}\text { Corrected } \\
\text { Item-Total } \\
\text { Correlation }\end{array}$ & $\begin{array}{l}\text { Alpha } \\
\text { if item } \\
\text { deleted }\end{array}$ \\
\hline $\begin{array}{l}\text { Social Self- } \\
\text { Interest }\end{array}$ & $\begin{array}{l}\text { Would most people be happy to sit } \\
\text { next to this man on a bus? }\end{array}$ & 0.702 & 0.5587 & 0.6747 \\
\hline (Distancing, Avoi- & $\begin{array}{l}\text { Would most people be happy to eat food which } \\
\text { he has cooked? }\end{array}$ & 0.657 & 0.5457 & 0.6812 \\
\hline $\begin{array}{l}\text { ding Association } \\
\text { with the Outcasts) }\end{array}$ & $\begin{array}{l}\text { Would most people avoid talking to him } \\
\text { if possible? }\end{array}$ & 0.589 & 0.5712 & 0.6657 \\
\hline Variance: 34.70 & $\begin{array}{l}\text { Would most people think he should stay in } \\
\text { hospital for his whole life? }\end{array}$ & 0.516 & 0.4825 & 0.7204 \\
\hline $\begin{array}{l}\text { Evolutionary } \\
\text { Self-Interest }\end{array}$ & $\begin{array}{l}\text { Would most people be happy if this person } \\
\text { became the teacher of their children? }\end{array}$ & 0.793 & 0.5944 & 0.6886 \\
\hline $\begin{array}{l}\text { (Genetic, Territorial, } \\
\text { Economic) }\end{array}$ & $\begin{array}{l}\text { Would most people be happy if he married } \\
\text { their sister? } \\
\text { Would most people be happy if he were to work }\end{array}$ & 0.775 & 0.6014 & 0.6852 \\
\hline Variance: 7.82 & together with them in their workplace? & 0.675 & 0.5751 & 0.7004 \\
\hline & $\begin{array}{l}\text { Would most people be frightened if this man } \\
\text { came to live next door to them? }\end{array}$ & 0.524 & 0.4823 & 0.7514 \\
\hline $\begin{array}{l}\text { Psychological } \\
\text { Self-Interest }\end{array}$ & $\begin{array}{l}\text { Do most people think one of the main causes } \\
\text { of his condition is a lack of moral strength }\end{array}$ & & & \\
\hline $\begin{array}{l}\text { (Projection, Personal } \\
\text { Guilt Management, } \\
\text { Allocation of } \\
\text { Responsibility) }\end{array}$ & $\begin{array}{l}\text { or will power? } \\
\text { Do most people think his condition is a } \\
\text { punishment for bad deeds? } \\
\text { Do most people think he has developed his } \\
\text { condition to avoid the difficult problems }\end{array}$ & 0.735 & 0.5458 & 0.7008 \\
\hline Variance: 15.03 & of everyday life? & 0.693 & 0.4817 & 0.7230 \\
\hline & $\begin{array}{l}\text { Do most people think he has become a failure } \\
\text { in his life? }\end{array}$ & 0.621 & 0.5290 & 0.7069 \\
\hline & $\begin{array}{l}\text { Would most people think this man is a } \\
\text { bad person? }\end{array}$ & 0.516 & 0.4733 & 0.7254 \\
\hline
\end{tabular}

instruments focus on one perspective for example culture without an effort to factor analyse and conceptualize stigmatization. Littlewood (1998) reviewed the content of personal explanatory model questionnaires (Kleinman 1980) given to patients and relatives in addition to recording patients' views about stigmatization derived from a weekly clinically applied anthropology group, a user group and mental health workers from various ethnic backgrounds. The result was the 26-item inter-cultural stigmatization questionnaire. Littlewood's questionnaire were rigorously screened and selected mainly from anthropological field studies. It assessed predisposition to enact stigmatization but not perception of stigmatization by users. It had neither a SD scale nor any rec- 
ommendation to include one. The intercultural stigmatization questionnaire constituted a large effort of compilation and scrutiny; nonetheless it was not subjected to standardization, factor analysis and abstraction of subconcepts of stigmatization.

Other scales had attempted to conceptualize stigmatization. The OMI and CAMI's conceptualizations include 'benevolence' (with items which measure good will towards patients) as a factor in the measurement of stigmatization, more benevolence suggesting less stigmatization. As such, these scales are at best a measure of community attitudes, both positive and negative, and not a pure measure of stigmatization. One can argue that a benevolent 'attitude' may indicate lower levels of stigmatization, yet it can also be expressed on a piece of paper to compensate for the stigmatization intended or already exercised and allay the related guilt. Indeed, Taylor \& Dear's (1981) study though not referring to the relationship between guilt and benevolence, supports this proposition. The 'benevolence' scores only weakly predicted the acceptance of mental health facilities in one's area. The authors admitted that the factor "suggests a transcendent sympathetic attitude towards the mentally ill which conceals important attitudinal variations." Also, benevolence can sometimes act as a double-edged sword designed unconsciously both to stigmatize more and to compensate for stigmatization. For example, a positive response to the following proposition: "More tax money should be spent in the care and treatment of people with mental illness" may mean benevolence but also participants' fear of people with mental illness, promoting the idea that patients must be treated more vigorously to reassure 'safety and security' for themselves and their families.

The Custodial Mental Illness Ideology (CMI) scale by Gilbert and Levinson (1956) was designed to assess the custodial ideologies of mental health workers decades ago, and contained items that showed a high correlation with the $\mathrm{F}$ scale which assesses authoritarian personalities (Adorno et al. 1950). A high score on CMI represented an authoritarian modal personality in the mental health worker (facilitated by selective recruitment, turnover, and personality change in the work context), and suggested coercive handling of patients in congruence with supervisory ideologies of the then mental health policies. Cohen \& Struening (1962) used some items from CMI and F Scale in a new scale called Opinion about Mental Illness (OMI) and, after a factor analysis, followed on Gilbert and Levinson (1956) and considered 'authoritarianism' to be a factor of stigmatization. This tradition trailed on into the work of Taylor \& Dear (1981) who, using the OMI and another scale: CMHI (Community Mental Health Ideology) (Baker \& Schulberg 1967), developed CAMI (Community Attitudes to Mental Illness) scale. Though they set out to develop an instrument to measure community rather than professional attitudes they followed the precedence and referred to one of the factors derived in their factor analysis as 'authoritarianism', so did Wolff et al. (1996) who nonetheless chose a more precise term, 'social control'. Around the same time when CMI was being developed, Cumming \& Cumming (1957) deployed another scale. A factor analysis of their instrument resulted in a social distance factor and a responsibility factor but no 'authoritarianism' factor. Is it sufficient to be authoritarian in order to stigmatize? Will this sort of nomenclature assist us in delineating the core components of stigmatization and understand its causes?

The results of this study indicated the roots of stigmatization. The question, 'Would most people think he should stay in 
hospital for his whole life?' was extracted by rigorous statistical analysis, in the same constellation of items as 'Would most people be happy to sit next to this man on a bus?', 'Would most people avoid talking to him if possible? and 'Would most people be happy to eat food which he has cooked?' Thinking of the underlying meaning, one can see that factor I contains elements suggesting distancing of patients into both mental institutions and margins of society. Exaggerating differences between in-groups and out-groups tend to obscure dissensions within the in-group (Townsend 1979) promoting in-group cohesion and ultimately serving the Social Self-Interest of the ingroup members. For example, when in the Middle Ages leprosy almost disappeared from Europe, the leprosaria had to be replaced by some other centre of confinement and seclusion. The so-called 'leper houses' were then offered to people with mental illness and criminals as if society needed to maintain a locus of exclusion where it could offload all its 'undesirables', for the social self-interest of others. It becomes clear that what the earlier authors recognized as 'authoritarianism' corresponds to this stigmatization factor more appropriately designated as Social SelfInterest by distancing of out-groups. It is just the case that authoritarian mental health workers in large mental hospitals were doing the job of distancing the 'mentally ill' on behalf of society. It was not the personality of mental health workers per se which was the cause of stigmatization, but the social and environmental forces which recruited and changed the personality of those assigned the task of keeping in custody those deemed as mentally ill. Today, this distancing or exclusion can present themselves when someone would not sit next to a someone with mental illness on a bus, would not eat food which he has cooked, avoid talking to him if possible, and wants him locked up for the rest of his life. Clearly, this someone does not need to be necessarily 'authoritarian' in order to stigmatize; he needs to marginalize, isolate or seclude.

\section{Factor II Evolutionary Self-Interest} (Table II) corresponds to the genetic selfinterest (would most people be happy if he married their sister?) and economic and territorial self-interest (would most people be happy if he were to work together with them?) etc. This makes sense when one considers that to increase one's chance of access to resources, stigmatization is used as a weapon in socio-economic competition (Sherif et al. 1961, Hatfield et al. 1978). The latter is likely to be more intense in more competitive, self-seeking societies, and moderated in turn by the ease of availability of resources. Those who are poor bets genetically (would most people be happy if they married their sister?); in terms of territory, and security (would most people be happy if he were to become the teacher of their children? Would most people be happy if he lived next door to them?) and/or in terms of co-productivity, economic competition and exaction of the resources (Would most people be happy if he were to work with them in their workplace?) are stigmatized in the service of genetic and economic self-interest.

Factor III corresponds to Psychological Self-Interest (Table II). (Do most people think one of the main causes of his condition is a lack of moral strength or will power? Do most people think his condition is a punishment for bad deeds? Do most people think he has become a failure in his life?), etc. In perceiving the other person as "bad", "failed" or "morally weak", people are likely to feel better about themselves. The discourse of someone who stigmatizes is likely to consist of 
"They are bad, so I am OK." The allocation of 'badness' and 'failure' to the other provides them with relative self-glorification and helps them downplay their own negative attributes by detracting full attention or awareness from self to discredited attributes of others. As such, people 'benefit' from the presence of the stigmatized (Haghighat 2001b) as the latter provide them with examples they would consider as "worse than them'. So stigmatization, even when it relates to an objective deficiency in the other, somehow serves stigmatizers in paying them $p s y$ chological dividends. To deal with any possible feelings of guilt the realization of the fate of people with mental illness may cause, they may resort to rationalisations such as the Just World Hypothesis (Lerner \& Miller 1978, Lerner 1980). The idea that someone can experience illness or injury, without being responsible, is threatening and we need reassurance that the same fate is not going to befall us. Some of us may then propose that the stigmatized have done something wrong and are being punished, deservedly, for bad deeds. This facilitates our pursuit of psychological self-interest without feeling guilty.

\section{C) The Unitary Theory of Stigmatization}

The concepts derived in this work are related to evolution, economic survival, genetics and our basic instincts and bahaviour probably related to the structure of our brain, i.e., the foundations of what we are. The SSQ was developed a few years ago and the unitary theory of stigmatization (Haghighat 2001c, 2003) emerged in the course of work on the final stages of development of the SSQ, coinciding with extraction of the factors and thinking on the meaning of the derived questions but before naming the factors and finishing the work.
The relentless character of stigmatization comes from the fact that it could be beneficial for stigmatizers so it happens even in situations when the stigmatized may not, in reality, possess the stigmatizing attribute or could have other attributes that claim balanced recognition and/or respect. Not only does stigmatization provide primary gain through relief of anxiety by avoidance and projection, it also provides secondary gain by avoiding a possible danger, loss or victimisation and by increasing the chances of economic survival. Stigmatization is tied so closely to self-interest that it provides tertiary gain too, for example dictators, by diverting the population's rage from themselves to certain stigmatized targets such as real or imagined internal or external enemies, maintain their power and so draw tertiary gain from stigmatization.

It might be argued that the seeking of selfinterest is the basis of most if not all human behaviour, yet the awareness that stigmatisation is a camouflaged yet radical version of pursuit of self-interest is likely to act as a strong antistigmatizing message with the constructive guilt that it may produce.

\section{Conclusion}

The result of this work is the Standardized Stigmatization Questionnaire (SSQ1) version 1. It has two parts, part I for the assessment of perceived stigmatisation, and Part II for the assessment of predisposition to enact stigmatization. Part II of the SSQ can be used either with the SD scale described above which has the advantage of brevity for some groups for example patients, or with a more comprehensive SD scale such as Crowne-Marlowe inventory (1960). 
Appendix I

Vignette used with Part I, and II of the questionnaire. In Part II, 'most people' was replace by 'yourself'

"Thank you for answering some questions about a person who becomes ill. We do not need your name. Please read carefully and then answer the questions about him. There are many differences of opinion on this subject. There are no right or wrong answers: we are simply interested in your opinion. Please answer every item. We do not require your name.

This man is twenty years old. He is not married and lives with his parents. One day he becomes ill and his doctor says he is a schizophrenic.

Now what do you think most people (but not yourself) would actually do or feel about this person if they knew his history. Please put a tick in the appropriate box for each question."

The SSQ was used in a relatively large survey of stigmatization in patients and relatives in Camden and Islington, UK and is being extensively used in Europe including countries such as Italy where it has been adopted for use in more than ten research institutions. The SSQ is likely to contribute to a more valid, reliable and rigorous assessment of stigmatization in future community surveys.

\section{References}

Adorno TW, Frenkel-Brunswick E, Levinson DJ et al. The Authoritarian Personality. New York: Harper; 1950.

Baker F, Schulberg H. The Development of a Community Mental Health Ideology Scale. Community Ment Health J 1967; 3: 216-225.

Brockman J, D'Arcy C, Edmons L. Facts or Artefacts? Changing Attitudes towards the Mentally Ill. Soc Sci Med 1979; 13A: 673-682.

Cohen J, Struening EL. Opinion about Mental Illness in the Personnel of Two Large Hospitals. J Abnorm Soc Psychol 1962; 5: 349-360.

Crisp A, Gelder MG, Rix S et al. Stigmatisation of People with Mental Illness. BJP 2000; 177: 4-7.

Cronbach LJ, Meehl PE. Construct Validity in Psychological Tests. Psychol Bull 1955; 52: 281-302.

Crowne DP, Marlowe DA. New Scale of Social Desirability Independent of Psychopathology. J Consult Psychol 1960; 24: 349-354.
Cumming E, Cumming J. Closed Ranks - An Experiment in Mental Health Education, Cambridge, MA: Harvard University Press; 1957.

Gilbert DC, Levinson D J. Ideology, Personality and Institutional Policy in the Mental Hospital. J Abnorm Soc Psychol 1956; 53; 263-271.

Haghighat RA. Preventive Strategy for Schizophrenia: from primitive drives to development of a new society. In: Grispini A ed. Intervention for Schizophrenic Disorders. Rome: Giovani Fioriti; 2003.

Haghighat R. Stigmatization of People with Schizophrenia [Dissertation]. University of London; 2001a.

Haghighat RA. Unitary Theory of Stigmatization. BJP 2001b; 178: 207-215.

Haghighat R. Towards A Unitary Theory of Stigmatization. BJP 2001c; 178; 378-381.

Kleinman A. Patients and Healers in the Context of Culture. Berkley: University of California Press; 1980.

Littlewood R. Cultural Variation in the Stigmatization of Mental Illness. Lancet 1998 Sep 26; 352(9133): 1056-7.

Rodeghier M. Surveys with Confidence. Chicago: SPSS Inc; 1996.

Shaw ME, Wright JM. Scales for the Measurement of Attitudes. New York: McGraw-Hill; 1967.

Taylor SM, Dear MJ. Scaling Community Attitudes toward the Mentally Ill, Schizophr Bull 1981; 7: 225-240.

Townsend J. Stereotypes of Mental Illness: A Comparison with Ethnic Stereotypes. Cult Med Psychiatry 1979 Sep;3(3):205-29.

Wolffe G, Pathare S, Craig T et al. Community Attitudes to Mental Illness. BJP 1996; 168: 183-190.

Address for correspondence:

Department of Psychiatry,

University College London Medical School,

UNITED KINGDOM

e-mail: r.haghighat@1ycos.com 